\title{
El costo del Estado confesional en Costa Rica: Implicaciones presupuestarias del financiamiento del Estado a la Iglesia Católica
}

Recibido: 24 de julio 2018 Revisado: 28 de agosto 2018 Aprobado: 8 de octubre 2018

Priscilla Carballo Villagra Costarricense. Máster en sociología de la Universidad de Costa Rica. Es investigadora del Centro de Investigación en Cultura y Desarrollo de la Universidad

Estatal a Distancia y consultora independiente. Trabaja temas de análisis de políticas públicas y estudios culturales. Correo electrónico: pcarballo@uned.ac.cr

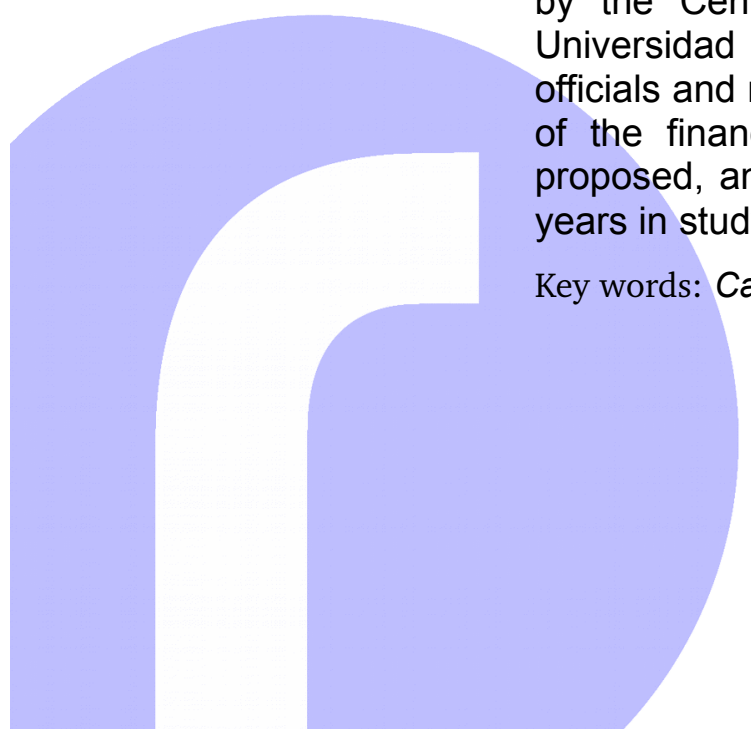

http://investiga.uned.ac.cr/rupturas/ (c) (1) (2) público
Resumen: El presente artículo expone los resultados de la investigación titulada: "Estado confesional en Costa Rica: implicaciones para las políticas públicas del financiamiento del Estado a la Iglesia católica 2014-2016", que se ejecutó desde el Centro de Investigación en Cultura y Desarrollo de la Universidad Estatal a Distancia. Por medio de la entrevista a una población de funcionarios y la solicitud de información a diversas instituciones, se plantea la base legal del financiamiento que el Estado le asigna a la Iglesia católica. A partir de esto, se exponen los montos asignados a dicha iglesia para los años en estudio. Todo esto a partir de cinco vías de canalización de fondos estudiadas.

Palabras clave: Iglesia católica; Estado; Estado confesional; presupuesto

\section{The Cost of the Confessional State in Costa Rica: Budgetary} Implications of State Funding to Catholic Church

Abstract: This article exposes the results of the research entitled: "Confessional State in Costa Rica: Implications for Public Policies of the State's Financing of the Catholic Church 2014 -2016.", Carried out by the Center for Research in Culture and Development of the Universidad Estatal a Distancia. Through an interview with public officials and request information to various institutions, the legacy base of the financing that the state assigns to the Catholic Church is proposed, and from this the amounts assigned to said church for the years in study.

Key words: Catholic church; State; confessional state; public budget 
El Estado costarricense es un Estado confesional, un Estado que ha asumido el compromiso de financiar parte del accionar de la Iglesia católica en el territorio. Pero cuando hacemos referencia al compromiso asumido por el Estado costarricense para direccionar fondos amparados en el artículo 75 de la Constitución Política, no tenemos claridad de cuánto cuesta mantener un Estado confesional en la Costa Rica contemporánea.

Con base en esas afirmaciones, se derivan varias preguntas: ¿cómo y cuándo se da ese acuerdo entre ambos actores para que el Estado direccione fondos a este actor religioso? ¿Qué instituciones aportan dinero a la iglesia? ¿Cuáles son los mecanismos utilizados para esto? ¿De cuánto dinero estamos hablando?

Nos dedicaremos a responder esas preguntas en el presente artículo, el cual expone resultados de investigación del proyecto titulado: "Estado confesional en Costa Rica: implicaciones para las políticas públicas del financiamiento del Estado a la Iglesia católica 2014-2016.", que se ejecutó desde el Centro de Investigación en Cultura y Desarrollo de la Universidad Estatal a Distancia. El trabajo de investigación consistió en revisión documental, solicitud de información en las instituciones respectivas y; finalmente, entrevista a una población de funcionarios y funcionarias públicas.

Las vías de financiamiento que se analizarán en este texto son las siguientes:

- Financiamiento por medio del Presupuesto General de la República, aprobado por Ministerio de Hacienda y Asamblea Legislativa.

- Financiamiento para mantenimiento de templos por medio del Centro de Investigación y Conservación del Patrimonio del Ministerio de Cultura.

- Financiamiento de centros de educación religiosos desde el Ministerio de Educación Pública.

- Donaciones de instituciones estatales vía Ley 7266 "Autorización a instituciones descentralizadas y empresas públicas del Estado para hacer donaciones a Fundación para restauración de Catedral Metropolitana y otros templos y monumentos católicos y empresas privadas a deducir impuesto sobre la renta".

- Exoneraciones de impuestos territoriales.

Para presentar esta información, a continuación, plantearemos el origen y el contexto de esta relación Iglesia-Estado. Posteriormente, explicaremos la Iglesia como administradora de sus bienes materiales. Después, para cada una de las cinco vías en estudio, abordaremos el referente legal que las sustenta y los montos asignados a la Iglesia, para los años 2014, 2015 y 2016, en los casos en que pudimos acceder a dichos datos. 


\section{El origen histórico del financiamiento de la Iglesia por parte del Estado costarricense}

Luego del proceso de la independencia en 1821, concretamente 31 años después, se firmó el primer Concordato en 1852, cuyos representantes fueron el arzobispo Llorente y la Fuente por parte del Vaticano; y Juan Rafael Mora Porras, por parte del Estado.

La firma de ese concordato fue muy estratégica en ese momento histórico como manera de resguardar beneficios que tenía la Iglesia y que venían de la época colonial: por lo tanto, se requería un instrumento que amparara el accionar del Estado a favor de la Iglesia. En este proceso de firma del Concordato, como se aprecia en el cuadro siguiente, ambos actores obtienen beneficios del proceso:

\section{Cuadro 1. Beneficios obtenidos por ambos actores en la firma del primer Concordato entre el Estado costarricense y el Vaticano en 1852}

\begin{tabular}{|c|c|}
\hline & \\
\hline $\begin{array}{l}\text { - La legitimidad en el territorio, al ser } \\
\text { reconocida como la religión del } \\
\text { Estado. } \\
\text { - La garantía de ser la encargada de } \\
\text { la educación religiosa. } \\
\text { - La potestad del obispo de revisar la } \\
\text { circulación de libros para prohibir su } \\
\text { difusión si eran contrarios a sus } \\
\text { determinaciones. } \\
\text { El Estado debe dotar de dinero a la } \\
\text { Iglesia para mantener al obispo, el } \\
\text { cabildo, el seminario y algunos } \\
\text { templos. } \\
\text { La exclusión del pago de impuestos } \\
\text { de los terrenos donde existen } \\
\text { templos católicos. }\end{array}$ & $\begin{array}{l}\text { - La demostración de la autonomía } \\
\text { económica frente al Estado del } \\
\text { Vaticano y evidencia que puede } \\
\text { mantener la diócesis. } \\
\text { - Derecho de Patronato, es decir, que } \\
\text { el presidente tenía que estar de } \\
\text { acuerdo en la designación de los } \\
\text { obispos y en el lugar geográfico de } \\
\text { los nuevos templos. } \\
\text { - El presidente podría nombrar, } \\
\text { además, a seis canónigos del } \\
\text { Cabildo. } \\
\text { El obispo y los clérigos debían } \\
\text { prestar juramento de fidelidad al } \\
\text { Gobierno. } \\
\text { Además, se incluye, al final de cada } \\
\text { misa, una oración para la protección } \\
\text { de la república y el presidente. }\end{array}$ \\
\hline
\end{tabular}

Fuente: Elaboración propia a partir de Sandí (2012).

Como se puede observar, con la firma del Concordato, se origina un proceso de legitimación recíproca de ambas instituciones. Además, en él se encuentra la base de dos elementos de financiamiento del Estado a la Iglesia católica que analizaremos en este artículo: el financiamiento vía presupuesto directo a la Iglesia y la exoneración de pago de impuestos, en este caso territoriales. 
Ahora bien, ¿por qué se incluye el financiamiento del Estado a la Iglesia en dicho concordato? Sandí (2012) plantea que, en 1852, se produce una fuerte disputa entre monseñor Llorente y la Fuente y el presidente Mora Porras. En ese periodo, ciertos sectores pagaban el diezmo a la Iglesia católica, de manera que el arzobispo hace una consulta al Vaticano para saber si las actividades vinculadas a la producción del café debían pagar impuestos y cuánto deberían pagar por ello. Esto genera una fuerte disputa con Mora Porras a quien le preocupa que el pago de este diezmo desincentive la incipiente actividad cafetalera que era muy importante para la economía del país. A partir de esto, en el marco del Concordato, el presidente Mora Porras decide pagar con dinero del Tesoro Nacional la manutención de varios miembros del clero, así como otros requerimientos de la diócesis:

La disposición de subvencionar al obispo, al cabildo, al seminario y a algunas parroquias fue con la finalidad de suplir la derogación de los diezmos ejecutada, paulatinamente, por el Gobierno de la república de Costa Rica desde 1825. En lo concerniente a los diezmos, la dotación que el Gobierno central de la república se había comprometido a pagar, por medio de Decreto CXXV, del 15 de julio de 1853, en los artículos 1 y 2 . Así se instauró que Roma exoneraba a los católicos del país a no pagar el diezmo a la Iglesia, permiso condicionado al compromiso del Estado de pagar diez mil pesos anuales. Los artículos 3 y 4 , por su parte, aludían al modo de pago mensual después del 5 de octubre de 1853 (Sandí 2012, 83).

De esta forma, encontramos el origen histórico que dio la base a las múltiples formas de financiamiento que encontramos en el Estado costarricense actual que, con los años, se van ampliando. Incluso durante y luego de la declaratoria de las leyes anticlericales de 1884, el Estado nunca dejó de financiar a la Iglesia y este presupuesto aumentó de manera sostenida, más bien el ámbito de financiamiento se amplió; por ejemplo, los siguientes mecanismos de financiamiento (Sandí 2012):

- En 1863, el Gobierno aporta dinero a la Iglesia para la construcción de la Catedral y del cabildo eclesiástico.

- En 1873 , se le otorga a la Iglesia tierras para explotar y financiar los templos de Puntarenas y Cartago.

- En 1874, paga salarios a sacerdotes de varias parroquias. 
- En 1878 , se brinda ayuda en pago de salarios a presbíteros y para construir los templos de Limón y de Golfo Dulce.

- En 1887, se exime de pago de impuestos de aduanas y el muellaje a artículos usados para el culto católico.

- Entre 1901 y 1920, el Estado expropia terrenos y brinda dineros para construir ermitas e iglesias en todo el país.

Así encontramos que los orígenes del financiamiento de la Iglesia al Estado se basan, en realidad, en un pacto entre élites oligarcas vinculadas a la actividad cafetalera que no quieren mermar sus ganancias con el pago del diezmo. Por lo tanto, el gobernante decide que el Estado sea el que cubra ese gasto dando del tesoro nacional recursos a la Iglesia.

Como lo plantea Sandí, este proceso de financiamiento se va ampliando y ramificando a diferentes instituciones públicas con el pasar del tiempo, debido a la capacidad de negociación de los jerarcas católicos con las élites políticas. En este aspecto, es necesario tener claro la relevancia del proceso de legitimación que podía darle la Iglesia al Estado, pues un país que hasta hace muy poco tiempo era mayoritariamente católico, esta legitimación era central para la clase política, por esto, el interés de articulación entre ambos.

\section{La Iglesia como administradora de sus bienes materiales}

La Iglesia católica es un actor inminentemente político y tiene una base económica desde la que administra una serie no pequeña de bienes materiales, parte de los cuales, como vimos, han sido donados o generados por el Estado costarricense. Para comprender las vías de financiamiento del Estado a la Iglesia, se debe conocer cómo la Iglesia administra parte de sus bienes, los cuales se entienden con el término de "temporalidades" de la siguiente manera:

Para poder desarrollar sus fines, los cuales son primordialmente espirituales, la Iglesia católica se apoya en bienes físicos, que se diferencian de los espirituales. A los primeros, la Iglesia los llama "temporales", ya que, según su doctrina, son usados únicamente en el tiempo que se está en la vida terrena y que, en el momento de avanzar a la vida eterna, ya no son necesarios, de ahí el concepto de temporales (García 2012, 163). 
De esta forma esos bienes son propiedad del Papa, pero evidentemente son administrados por otras personas. En este caso, las diócesis los administran y el llamado Derecho Canónico establece los requisitos y las obligaciones que tienen quienes los administran.

Ahora bien, la Iglesia católica tenía, desde el periodo colonial, temporalidades; pero su posesión de bienes no estaba claramente regulada, pues la Iglesia no tenía personería jurídica bajo la cual inscribirlas. A partir de 1901, se les da un poder de representación a las diócesis para administrar estas temporalidades. Pero, en 1977 a partir de la aprobación de la Ley 6062 Ley de personería jurídica de la Conferencia Episcopal de Costa Rica y de las Diócesis Eclesiásticas, otorga dichas personerías a la Conferencia Episcopal y a las diferentes diócesis del país. Como plantea García:

La Conferencia Episcopal se inscribe en el Registro de Personas Jurídicas como tal, más cada una de las diócesis se inscribe, no como órgano eclesial que es, sino que se inscribe como la separación de la masa de bienes temporales de cada una de ellas, resultando así el nacimiento jurídico propiamente dicho, y el nacimiento registral de las temporalidades de cada una de las diosésis que componen la Provincia Eclesiástica de Costa Rica. (García 2012, 173)

De hecho, cada una de las diócesis del país tiene, para administrar sus bienes, una cédula jurídica bajo el nombre "Temporalidades de la Arquidiócesis de...", con las cuales, como establece la Ley 6062, pueden realizar actos y contratos que establezcan las leyes vigentes del país.

Para terminar de comprender la naturaleza jurídica que le da sustento a la Iglesia como actor económico, debemos mencionar que, posteriormente en el 2005, se establece el Reglamento 32370 titulado "Reglamento que Desarrolla los Alcances de la ley que otorga personería jurídica a la Conferencia Episcopal y Diócesis Eclesiásticas señalando la situación de los órganos que componen la Iglesia Católica", en el que, en el ámbito legal, se reconoce lo siguiente:

Artículo 1. Este Reglamento tiene por objeto desarrollar los alcances de la Ley № 6062, del 8 de julio de 1977, señalando la situación jurídica de todos los órganos que componen la Iglesia católica, respetando la normativa 
eclesiástica y el libre ejercicio de sus actividades, tanto en el orden espiritual como en el temporal.

Artículo 2. Para los efectos de este reglamento, se considera parte de la Iglesia católica en Costa Rica los siguientes:

1. Personas jurídicas canónicas: a. Conferencia Episcopal Nacional, b. Diócesis o iglesias particulares, c. Iglesia catedral, d. Parroquias y Cuasiparroquias, e. Rectorías, f. Capellanías y g. Cualquier otra persona jurídica pública de la Iglesia conformada, según el Código de Derecho Canónico de la Iglesia Católica.

2. Jerarquía de la Iglesia: a. Obispos (tanto diocesanos, auxiliares o coadyutores y eméritos), b. Presbíteros y c. Diáconos.

3. Otros grupos o de Vida Consagrada: a. Institutos religiosos, b. Institutos seculares, c. Sociedades de Vida Apostólica.

Artículo 3. Se entiende por derecho interno de la Iglesia católica el conjunto de disposiciones y normas que rigen la organización interna y las actividades de dicha iglesia, que incluyen: el Código de Derecho Canónico, el Derecho Eclesiástico Universal y el Derecho Eclesiástico Particular. Todos ellos tendrán el valor y alcance que la propia Iglesia católica les confiere y surtirán los efectos jurídicos para los sujetos y las relaciones por ellas reguladas.

Artículo 4. Se reconoce a la Conferencia Episcopal Nacional de Costa Rica, así como a cada una de las diócesis, la facultad de dictar las directrices, políticas y reglamen- 
tos que regirán los órganos e instituciones que las integran respectivamente, así como la definición de sus competencias y estructura funcional.

Artículo 5. Para el cumplimiento de sus fines, la Iglesia católica podrá adoptar la organización institucional prevista en su ordenamiento interno, así como utilizar las formas jurídicas autorizadas en la legislación común.

Con este reglamento, se terminan de reconocer no solo las arquidiócesis, sino el resto de instituciones que figuran en el ordenamiento de la Iglesia. La finalidad con estas legislaciones es poner en regla los derechos particulares que ya tenía la Iglesia católica; pero fundamentalmente, les permite hacer transacciones legales de ventas, compras y contrataciones, así como la redireccionalización de fondos por parte del Estado con mayor facilidad, pues la incertidumbre jurídica que estas temporalidades de la Iglesia católica tenían limitaban este accionar.

Ahora bien, aunque no es el foco de atención de este proceso de investigación, en los últimos años, concretamente del 2008 en adelante, se han dado escándalos mediáticos sobre la forma de administrar esos bienes materiales por parte de la Conferencia Episcopal. Por ejemplo, en el 2008, la Superintendencia General de Entidades Financieras (Sugef) denuncia a la Conferencia por el delito de intermediación financiera y, en ese año, la fiscalía allana esa entidad religiosa. En los últimos años, se han dado varios cuestionamientos de la Sugef sobre estos manejos económicos de la Iglesia y las inversiones que se hacen desde esta entidad.

A partir de los planteamientos anteriores, se puede evidenciar cómo el Estado costarricense ha creado legislaciones y reglamentos para el reconocimiento de la Iglesia como administradora de bienes y ha organizado los marcos legales para poder realizar transferencias de fondos.

Teniendo esta base de reconocimiento legal de las figuras jurídicas de la Iglesia como administradora de sus temporalidades, analizaremos los principales mecanismos de financiamiento que se efectúan desde el Estado.

\section{Financiamiento por medio del Presupuesto General de la República}

La Asamblea Legislativa aprueba el Presupuesto General de la República y, en este proceso, están incluidos algunos montos específicos destinados a la Iglesia católica. Para acceder a los datos sobre el monto del Presupuesto 
General de la República, se dirigió la consulta al jefe de área del Departamento de Análisis Presupuestario de la Asamblea Legislativa, señor José Rafael Soto, que es el departamento que brindó los datos que se presentan a continuación:

Como veremos en el cuadro siguiente, los fondos se asignan a las temporalidades de la Iglesia católica de cada zona que, como expusimos anteriormente, es la entidad económico-administrativa de la Iglesia católica como institución.

Para este trabajo, se hizo el cotejo de la información a fin de que los montos suministrados por la Asamblea Legislativa no estuvieran duplicados en los brindados por las otras instituciones analizadas en los siguientes apartados.

En los montos siguientes, podemos apreciar partidas específicas para arreglos estructurales de iglesias que, si bien se direccionan por medio de Ministerio de Cultura, no son los fondos que se deciden por medio del Centro de Investigación y Conservación de Patrimonio de Ministerio de Cultura que analizaremos más adelante, sino que son partidas específicas; también se direccionan fondos por medio de Ministerio de Relaciones Exteriores y Culto. En ambos casos, la justificante es, de manera general, el artículo 75 de la Constitución Política, aunque este no refiere a la obligatoriedad de montos concretos. Además, encontramos un monto constante asignado a la Iglesia católica para el Archivo Histórico Arquidiocesano, amparado en la Ley 6475 denominada "Remodelación del Archivo Arquidiocesano" de 1980, en la que se establece lo siguiente:

Artículo 2. El Poder Ejecutivo incluirá, en el próximo pro-

yecto de ley de presupuesto, las partidas suficientes para

dotar al Archivo de la Curia Metropolitana de personal

técnico, que lo atienda y mantenga abierto al público.

Los datos recopilados para esta vía de financiamiento en el periodo de estudio pueden observarse en el cuadro 2. Es importante recordar que esta asignación presupuestaria se discute como parte del Presupuesto General de la República, basado en la confesionalidad del Estado. Ahí se aprueban estos montos con el aval de las fracciones legislativas.

A lo largo de este texto, veremos cómo diferentes instituciones asumen "de oficio" el financiamiento que se brinda a la Iglesia. De hecho, no existen grandes discusiones en estas instancias sobre los montos que se ofrecen o la posibilidad de recortarlos, lo cual muestra la naturalización de estos financiamientos dentro de la política y la burocracia en el país. 
Cuadro 2. Montos asignados a las temporalidades de la Iglesia católica por medio del Presupuesto General de la República durante los periodos 2014, 2015 y 2016

\begin{tabular}{|c|c|c|}
\hline Descripción & Monto & $\begin{array}{c}\text { Título } \\
\text { presupuestario }\end{array}$ \\
\hline \multicolumn{3}{|l|}{ Año 2014} \\
\hline $\begin{array}{l}\text { Temporalidades de la Arquidiócesis de San José (para } \\
\text { la joya arquitectónica templo católico San Isidro de } \\
\text { Heredia, artículo } 75 \text { de la Constitución Política de la } \\
\text { República de Costa Rica). } \\
\text { Temporalidades de la Diócesis de Tilarán (para la } \\
\text { construcción de la Parroquia Nuestra Señora del }\end{array}$ & 100000000 & $\begin{array}{l}\text { Ministerio de } \\
\text { Relaciones } \\
\text { Exteriores y Culto }\end{array}$ \\
\hline $\begin{array}{l}\text { Carmen, Barrio Unión de Cañas } \phi 100 \text { millones; para } \\
\text { mejoras de la capilla San Luis de la Parroquia Patriarca } \\
\text { San José de Cañas centro } \phi 50 \text { millones; para la } \\
\text { construcción de la concha de la parroquia La } \\
\text { Inmaculada de Colorado } \phi 50 \text { millones, artículo } 75 \text { de la } \\
\text { Constitución Política de la República de Costa Rica ). }\end{array}$ & 200000000 & $\begin{array}{l}\text { Ministerio de } \\
\text { Relaciones } \\
\text { Exteriores y Culto }\end{array}$ \\
\hline $\begin{array}{l}\text { Temporalidades de la Arquidiócesis de San José (para } \\
\text { el Archivo Histórico Arquidiocesano, según Ley } 6475 \\
\text { del 25/09/1980). }\end{array}$ & 15000000 & $\begin{array}{l}\text { Ministerio de } \\
\text { Cultura y Juventud }\end{array}$ \\
\hline \multicolumn{3}{|l|}{ Año 2015} \\
\hline $\begin{array}{l}\text { Temporalidades de la Arquidiócesis de San José (para } \\
\text { el Archivo Histórico Arquidiocesano, según Ley } 6475 \\
\text { del 25/09/1980). }\end{array}$ & 15000000 & $\begin{array}{l}\text { Ministerio de } \\
\text { Cultura y Juventud }\end{array}$ \\
\hline $\begin{array}{l}\text { Temporalidades de la Arquidiócesis de San José (para } \\
\text { reforzamiento estructural del templo parroquial } \\
\text { Inmaculada Concepción de Heredia artículo } 75 \text { de la } \\
\text { Constitución Política de la República de Costa Rica). }\end{array}$ & 450000000 & $\begin{array}{l}\text { Ministerio de } \\
\text { Cultura y Juventud }\end{array}$ \\
\hline
\end{tabular}

\section{Año 2016}

Temporalidades de la Arquidiócesis de San José (para el Archivo Histórico Arquidiocesano, según Ley 6475 del 25/09/1980).

Fuente: Departamento de Análisis Presupuestario. Asamblea Legislativa (2017).

\section{Financiamiento para cuidado de templos por medio de Centro de Investigación y Conservación del Patrimonio Cultural del Ministerio de Cultura}

La Iglesia católica, dada la antigüedad de su permanencia en el territorio, tiene una gran cantidad de edificaciones declaradas como patrimonio. Esto genera que el Ministerio de Cultura canalice, de manera sostenida, fondos para su conservación. En seguida veremos el marco legal y los montos asignados por esta vía. 
En relación con el financiamiento de restauración de templos vía Ministerio de Cultura, se regula a partir de la Ley 7555 titulada "Ley Patrimonio histórico-arquitectónico de Costa Rica", esta ley instituye el interés de parte del Estado de preservar el patrimonio material; y en su artículo 2, establece:

Artículo 2. Patrimonio histórico-arquitectónico: forma parte del patrimonio histórico-arquitectónico del país, el inmueble de propiedad pública o privada con significación cultural o histórica, declarado así por el Ministerio de Cultura, Juventud y Deportes de conformidad con la presente ley.

Se declaran de interés público la investigación, la conservación, la restauración, la rehabilitación y el mantenimiento del patrimonio histórico-arquitectónico.

La Comisión Nacional de Patrimonio Histórico-Arquitectónico se encarga de hacer las investigaciones necesarias para establecer una declaratoria de una estructura como patrimonio; y a partir de esto, se define una serie de obligaciones del propietario del bien, sea público o privado, para la conservación. Esto bajo la supervisión de la Oficina de Patrimonio.

En cuanto a los incentivos de parte del Estado para la conservación de este patrimonio, dicha ley establece los siguientes:

- Se deduce del impuesto de renta las donaciones e inversiones que se hagan para mantenimiento de estos lugares (art. 13).

- Las estructuras declaradas patrimonio quedan exentas de impuestos de bienes inmuebles y del impuesto sobre construcciones suntuarias, y de pago de timbres (art. 14).

- Las instituciones públicas pueden hacer donaciones e inversiones a obras (art. 15).

- Ministerio de Cultura puede gestionar ante los bancos líneas de crédito para particulares para la conservación y restauración de estos bienes declarados (art. 17).

Las edificaciones que son declaradas patrimonio por el Ministerio de Cultura, en la actualidad, son 367 inmuebles en total, ubicadas en todo el país. De estas, 58 son propiedad de las temporalidades de la Iglesia católica y contempla templos, ermitas, capillas, ruinas, basílicas y casas. Es la institución con más bienes a su cargo declarados como patrimonio.

En relación con las asignaciones de fondos, el Centro de Investigación y Conservación del Patrimonio del Ministerio de Cultura tiene dos formas por 
las cuales se entrega financiamiento para el mantenimiento de estructuras: la primera es mediante las inversiones directas que se deciden desde esta instancia para reparar un inmueble; y segundo, con los concursos denominados "Salvemos Nuestro Patrimonio".

En el primer caso de presupuesto que se destina para reconstrucción o mejora de instalaciones declaradas patrimonio, desde el Centro de Investigación y Conservación del Patrimonio Cultural, se define las edificaciones prioritarias y los montos de las obras, y esto se contrata por licitaciones. Los montos destinados a restauración de edificaciones de las temporalidades de la Iglesia católica en el periodo en estudio se aprecian en el cuadro 3.

Cuadro 3. Montos asignados al mantenimiento de temporalidades de la Iglesia católica por parte del Centro de Conservación del Patrimonio Cultural de Ministerio de Cultura para los periodos 2014, 2015 y 2016

\begin{tabular}{|c|c|}
\hline Edificación & Monto en colones \\
\hline $\begin{array}{l}\text { Obras de restauración del templo parroquial de San } \\
\text { Rafael de Heredia }\end{array}$ & 94700000 \\
\hline Total para el 2014 & 94700000 \\
\hline $\begin{array}{l}\text { Obras de consolidación de estructura de tempo colonial } \\
\text { de San Blas de Nicoya }\end{array}$ & 195000000 \\
\hline Total para el 2015 & 195000000 \\
\hline \multirow{3}{*}{$\begin{array}{l}\text { Restauración del templo de Toledo de Guatil de Acosta } \\
\text { Restauración de ventanas del templo de Copey de Dota } \\
\text { Consolidación de estructura del templo de San Blas de } \\
\text { Nicoya } \\
\text { Cambio de sistema eléctrico para el tempo de San } \\
\text { Antonio de Escazú }\end{array}$} & $\begin{array}{l}47012602 \\
10000000\end{array}$ \\
\hline & 156865123 \\
\hline & 30500000 \\
\hline Total para el 2016 & 244377725 \\
\hline
\end{tabular}

Fuente: Información suministrada por Centro de Investigación y Conservación de Patrimonio Cultura del Ministerio de Cultura mediante oficio CICPC-DI-1831-2017.

Como se puede observar en el cuadro anterior, los montos varían dependiendo la definición de prioridades que establece la comisión, pero todos los años se asigna, de manera constante, financiamiento a la Iglesia para sus diferentes estructuras. Según entrevista al señor William Monge, director del Centro de Investigación y Conservación del Patrimonio, la constante es que se dan sumas de entre cien y doscientos cincuenta millones de colones para diferentes obras a la Iglesia católica al año.

El otro mecanismo de canalización de fondos, como ya se mencionó, es el Concurso Salvemos Nuestro Patrimonio, en el que un arquitecto, o un grupo de ellos, propone una obra de restauración y un jurado define a un único proyecto por año como ganador. Al respecto en la entrevista sostenida con el señor William Monge, para los periodos en estudio (2014, 2015 y 2016), ninguno de los proyectos ganadores fueron estructuras pertenecientes a las temporalidades de ninguna de las diócesis de la Iglesia católica. 
Evidentemente, por la antigüedad de sus edificaciones y su cantidad, se plantea desde esta oficina que la entidad con la que mantienen mayor relación en términos de restauración es con la Iglesia católica. De esta manera, existe una canalización de fondos anual sostenida a esta institución religiosa.

Financiamiento de centros de educación religiosa por parte del Ministerio de Educación Pública

En relación con el tema del financiamiento a las instituciones de educación religiosa católica por parte del Ministerio de Educación, se encuentra, al igual que los anteriores mecanismos, amparado en instrumentos legales. En este caso, encontramos que cada vez se ha ido regulando más estos montos, fundamentalmente, para garantizar su asignación y no para su mejor fiscalización. Sin embargo, aunque los montos asignados son bastante altos, en el transcurso de los años, se han dado varios recortes.

Como señala el señor Mainor Villalobos, jefe de la Dirección de Educación Privada del MEP, en entrevista realizada para este proceso de investigación, en 1992, se realiza un recorte de los beneficios que se les da a estos colegios católicos en relación con las juntas de educación y el Patronato Escolar, pues se les asignaban beneficios similares a los colegios públicos. Este recorte se produce gracias a la intervención de la Contraloría General de la República que plantea que esta asignación no procede. Al parecer, según comenta el señor Villalobos, esta instancia le ha llamado la atención en varios momentos al MEP por la falta de mecanismos claros para asignar apoyos financieros a dichas instituciones.

Según entrevista realizada y a partir de la revisión de fuentes documentales y legales, el Ministerio de Educación brinda financiamiento a estas instituciones de educación católica a partir de las siguientes cuatro bases legales:

1. Ley 8791 titulada "Estímulo estatal de pago de salarios del personal docente y administrativo de las instituciones privadas de enseñanza" del año 2009.

2. Decreto Ejecutivo 33550 "Reglamento del Otorgamiento de Estímulos a la Iniciativa Privada en Materia de Educación por Parte del Ministerio de Educación Pública" del año 2006.

3. Ley 7157 "Ley de Creación de la Ciudad de los Niños" del año 1990.

4. Ley 6238 "Ley de operación del Colegio agropecuario de San Carlos" del año 1998.

Todos estos instrumentos legales se amparan en el artículo 80 de la Constitución Política, en el cual se establece que la educación privada puede ser objeto de estímulos por parte del Estado. Y se basa, además, en dos supuestos: el carácter social de estas instituciones educativas y que, en ellas, existe 
un proyecto educativo alternativo; pero como veremos más adelante, estos aspectos se cuestionan en la actualidad.

A continuación, se explica, de manera detallada, cada una de estas leyes; además, se contemplan los datos presupuestarios respectivos.

Con respecto al primer mecanismo legal de financiamiento, está lo referente a la Ley 8791 Estímulo estatal de pago de salarios del personal docente y administrativo de las instituciones privadas de enseñanza, del año 2009. Esta fija estímulos específicos para instituciones de educación lideradas por grupos católicos al plantear, en su artículo 6, lo siguiente:

Artículo 6. Requisitos. Las entidades solicitantes, de conformidad con lo establecido en el artículo 2 de esta ley, solo podrán ser sujetos del estímulo estatal cuando cumplan los siguientes requisitos y condiciones:

a) No tener fines de lucro.

b) Estar administradas, regentadas por alguna iglesia o congregación religiosa o estar administradas por alguna fundación o asociación con proyección social.

c) Tener el respectivo reconocimiento oficial extendido por el Ministerio de Educación Pública, en el que se equiparen los estudios que ofrece con los de la educación oficial.

d) Estar al día en el pago de sus obligaciones tributarias nacionales y municipales, así como en sus obligaciones patronales con el régimen de seguridad social.

e) Contar con los permisos sanitarios y municipales de funcionamiento correspondientes.

f) Garantizar el acceso a las personas estudiantes sin discriminación contraria a la dignidad humana.

g) Contar con un programa de becas hasta para un diez por ciento (10\%) de estudiantes en condición de 
pobreza o pobreza extrema o cuya situación socio económica lo amerite. Los alcances y las condiciones de estos programas deberán regularse en los respectivos convenios, según lo dispuesto en esta ley.

h) Suscribir un convenio con el Ministerio de Educación Pública, a efectos de establecer la regulación bilateral que disponga las condiciones en que se pondrá en marcha el estímulo, de conformidad con esta ley y su reglamento.

En esa ley se establece, además, que el Estado no podrá invertir más del $0,7 \%$ del presupuesto de educación en este punto. Es importante señalar que según lo plantea el señor Mainor Villalobos, jefe del Departamento de Educación Privada del MEP, se les paga el salario a funcionarios públicos interinos; en la función pública, se les denomina "funcionarios públicos destacados en centros educativos privados".

Según lo registra la página web oficial de Anadec (Asociación Nacional de Educación Religiosa), se tienen reportados 38 colegios católicos en el país distribuidos de la siguiente manera: San José 23, Heredia 6, Alajuela 3, Cartago 2, Limón 1, Guanacaste 2 y Puntarenas 1 (Anadec). Pero de estos centros, no todos reciben dinero del MEP, ya que según datos suministrados por la Dirección de Educación Privada de esta institución, los centros con asignación presupuestaria y sus respectivos montos para los periodos de estudio son los que se muestran en el cuadro 4.

Por medio de esta ley, se brinda la mayor cantidad de financiamiento a estas instituciones educativas privadas; y dicha herramienta jurídica no cierra, en ningún momento, el límite de centros educativos que pueden optar por tal beneficio. Al respecto, la única forma de rechazo de la solicitud de financiamiento si un centro educativo cumple con todos los requisitos es que no exista presupuesto, pero si cumple los requisitos y existe presupuesto, se aprueba el financiamiento al centro educativo, siempre que no sobrepase el $0,7 \%$ del presupuesto del MEP como establece esta ley.

Cabe señalar que todas estas instituciones educativas, como sus nombres evidencian, son católicas, y no existe ninguna institución de otras religiones. En relación con la ausencia de financiamiento de colegios de otras denominaciones religiosas, el señor Mainor Villalobos plantea que, en el pasado, existieron dos colegios evangélicos a los que se les daba financiamiento, pero que se les retiró el dinero. 
Cuadro 4. Montos asignados a centros educativos católicos por el MEP según la Ley 8791 para los periodos 2014, 2015 y 2016

\begin{tabular}{|c|c|c|c|c|}
\hline Dependencia & 2014 & 2015 & 2016 & Total general \\
\hline María Auxiliadora & 77335396 & 164706502 & 169244830 & 511286728 \\
\hline Niño Jesús de Pr & 86368852 & 87186768 & 85701309 & 259256928 \\
\hline Nuest & 327624787 & 331129031 & 323223499 & 981977317 \\
\hline $\begin{array}{l}\text { Centro Educativo Niño } \\
\text { Jesús de Belén }\end{array}$ & 15756679 & 15211094 & 13222050 & 44189823 \\
\hline Escuela Renzo Zingone & 10825227 & 9832136 & 10668788 & 31326151 \\
\hline $\begin{array}{l}\text { Instituto de Educación In- } \\
\text { tegral }\end{array}$ & 113536877 & 113001203 & 114463548 & 341001628 \\
\hline Liceo María inmaculada & 310452481 & 313849487 & 315629395 & 939931362 \\
\hline & 433266131 & 432216789 & 448129061 & 1313611980 \\
\hline Liceo & 218282023 & 195487332 & 205040905 & 618810260 \\
\hline Liceo & 173989135 & 169365447 & 169113180 & 512467761 \\
\hline & 337244762 & 336693925 & 352272463 & 1026211150 \\
\hline Liceo & 227248960 & 227776966 & 235309408 & 334 \\
\hline Liceo & 195166455 & 201049490 & 190337777 & 586553722 \\
\hline Liceo $\mathrm{F}$ & 377463376 & 374906217 & 390983731 & 1143353324 \\
\hline & 262173285 & 276125502 & 292134330 & 830433117 \\
\hline & 503387940 & 507740745 & 533445461 & 1544574145 \\
\hline & 433888968 & 428278894 & 435092140 & 1297260002 \\
\hline $\begin{array}{l}\text { Liceo Santa María de } \\
\text { Guadalupe }\end{array}$ & 753965441 & 758691593 & 763272967 & 2275930000 \\
\hline Liceo & 571738726 & 551965247 & 558103142 & 1681807114 \\
\hline Nuestra Señora & 153921122 & 163753032 & 166188021 & 483862175 \\
\hline \multirow[t]{2}{*}{ C.T.P. Don Bosco } & 1066056983 & 1041747614 & 1079045126 & 3186849723 \\
\hline & 6749693605 & 6700715008 & 6850621131 & 20301029744 \\
\hline
\end{tabular}

Fuente: Asesoría legal de la Dirección de Educación Privada del MEP.

Con respecto al segundo mecanismo legal de financiamiento, este es el Decreto Ejecutivo 33550 denominado "Reglamento del otorgamiento de estímulos a la iniciativa privada en materia de educación por parte del Ministerio de Educación Pública", esta normativa se genera en el año 2006. En la ley, se norma el mecanismo de asignación presupuestaria, lo cual crea varios conflictos con los colegios que, en ese momento, se les denomina semioficiales o subvencionados, incluso hacen manifestaciones en las afueras del MEP pues consideran que se verán afectados estos fondos. Muy por el contrario, la normativa tipifica las ayudas y los requisitos para darlas, de manera que no se originan, en este proceso, recortes. En su artículo 3 establece lo siguiente: 
Artículo 3. Tipología de estímulos que otorga el MEP. En aplicación de lo dispuesto en el artículo 80 de la Constitución Política y sobre la base del interés público, se determina que el Ministerio de Educación Pública podrá otorgar los siguientes tipos de estímulos, sea en forma conjunta o separada, a saber:

a) (Derogado por el artículo 20 del Reglamento a la Ley de Estímulo Estatal de Pago de Salarios del Personal Docente y Administrativo de las Instituciones Privadas de Enseñanza, aprobado mediante Decreto Ejecutivo 36895, del 10 de noviembre del 2011)

b) Transferencia de recursos económicos (dinero), con el fin de brindar soporte en algún proceso educativo de particular interés o el pago de educadores contratados en relación laboral común por el centro educativo privado, conforme el interés público.

c) Participación de los docentes del centro privado, en algún proceso de capacitación a educadores que organice o financie el Ministerio de Educación Pública, para sus servidores.

d) Participación de la comunidad estudiantil de un centro privado, en actividades culturales o de promoción educativa (tales como ferias científicas, etc.), que organice el Ministerio de Educación dentro del Sistema Educativo Público.

e) Préstamo o arrendamiento de instalaciones educativas propiedad del Ministerio de Educación Pública. 
f) Cualesquiera otras modalidades de estímulo que se consideren oportunas y sean previamente autorizadas por la Contraloría General de la República para su utilización.

Bajo esta normativa, solo se le asigna presupuesto a la Diocésis de Tilarán que tiene cuatro instituciones educativas a su cargo, de primaria y secundaria, a las cuales se les asignan los siguientes montos en los periodos de estudio:

Cuadro 5. Montos asignados a instituciones educativas católicas por el MEP según el Decreto Ejecutivo 33550

\begin{tabular}{|c|c|c|c|}
\hline Institución & 2014 & 2015 & 2016 \\
\hline Centro Educativo San Ambrosio & 88252412 & 91782508 & 95453808 \\
\hline Centro Educativo Eulogio López Obando & 42512644 & 44213150 & 45981676 \\
\hline Centro Educativo San Daniel Comboni & - & - & - \\
\hline Instituto Educativo San Jorge & 33802968 & 35155087 & 36561290 \\
\hline $\begin{array}{l}\text { Total Diócesis de Tilarán subprograma } 01 \\
\text { (PRIMARIA) }\end{array}$ & 164568024 & 171150745 & 177996774 \\
\hline Centro Educativo San Ambrosio & 148581493 & 154524753 & 160705743 \\
\hline Centro Educativo Eulogio López Obando & 34226607 & 35595671 & 37019498 \\
\hline Centro Educativo San Daniel Comboni & 22093692 & 22977440 & 23896537 \\
\hline Instituto Educativo San Jorge & 26077476 & 27120575 & 28205398 \\
\hline $\begin{array}{l}\text { Total Diócesis de Tilarán subprograma } 02 \\
\text { (SECUNDARIA) }\end{array}$ & 230979268 & 240218439 & 249827176 \\
\hline
\end{tabular}

Fuente: Asesoría legal de la Dirección de Educación Privada del MEP.

Como tercer mecanismo legal, existe la Ley 7157 "Ley de Creación de la Ciudad de los Niños”, denominada Centro Técnico San Agustín Ciudad de los Niños. Es una institución privada de interés social, pero con una junta directiva conformada por cinco miembros; de los cuales, tres son elegidos por la Conferencia Episcopal, uno del PANI y uno más del Consejo Municipal de la Municipalidad de Cartago. Y en su artículo 16, se establece que el Estado debe cubrir los salarios del director y de los funcionarios docentes y administrativos-docentes. Además, en los transitorios II y III, se define lo siguiente:

Transitorio II. Si en el futuro se derogara esta ley y esto ocasionara la disolución de la Ciudad de los Niños, los bienes inmuebles pasarán a las temporalidades de la Arquidiócesis de San José, y los muebles y demás derechos pasarán a la Municipalidad del cantón central de Cartago. 
Transitorio III. La Conferencia Episcopal de Costa Rica seleccionará a los tres miembros de la Junta Directiva, de una nómina enviada por el superior mayor de los padres agustinos recolectos, mientras dicha comunidad religiosa se mantenga al frente de la Ciudad de los Niños.

De esta entidad, los datos facilitados por el MEP son los siguientes:

\begin{tabular}{|c|c|c|c|}
\hline Institución & Año 2014 & Año 2015 & Año 2016 \\
\hline $\begin{array}{l}\text { Centro Técnico San Agustin } \\
\text { Ciudad de los Niños }\end{array}$ & 632902777 & 664547916 & 691129832 \\
\hline
\end{tabular}

Fuente: Asesoría legal de la Dirección de Educación Privada del MEP.

Finalmente, como último mecanismo legal, tenemos la Ley 6238 "Ley de operación del Colegio Agropecuario de San Carlos" en la cual se establece lo siguiente:

Artículo 1. El Estado reconoce el mérito de la labor desarrollada por el Colegio Agropecuario de San Carlos, desde su fundación hasta la fecha. Su desempeño originó y ha promovido en Costa Rica la educación agropecuaria de nivel medio, bajo el patrocinio del Instituto Agropecuario Costarricense Sociedad Anónima, hoy propiedad exclusiva de la Conferencia Nacional Episcopal de Costa Rica y con subvenciones anuales del Estado; asimismo, reconoce a la Escuela Técnica Agrícola e Industrial como una segunda etapa del desarrollo de la enseñanza técnica productiva patrocinada por el Instituto Agropecuario Costarricense S. A., con los planes y los programas de estudio aprobados por el Consejo Superior de Educación y con los mismos beneficios y obligaciones que actualmente tiene el Colegio Agropecuario de San Carlos, según la ley. 
Artículo 2. A partir de la promulgación de esta ley, el Estado asumirá los costos totales de operación y funcionamiento del Colegio Agropecuario de San Carlos y de la Escuela Técnica Agrícola e Industrial. Por su parte, el Instituto Agropecuario Costarricense Sociedad Anónima continuará a cargo de los costos de mantenimiento de los edificios y las instalaciones de ambos centros de educación.

Los montos asignados a partir de esta ley para los periodos de estudio son los siguientes:

Cuadro 7. Montos asignados a instituciones educativas católicas según Ley 6238 durante los periodos 2014, 2015 y 2016

\begin{tabular}{cccc}
\hline Institución & Año 2014 & Año 2015 & Año 2016 \\
\hline Colegio Agropecuario San Carlos & 991090710 & 1154501094 & 1451625948 \\
\hline
\end{tabular}

Fuente: Asesoría legal de la Dirección de Educación Privada del MEP.

Como podemos observar, es evidente que esta vía de financiamiento para centros de educación liderados por organizaciones religiosas (de las cinco vías que estamos analizando) es la que más canaliza fondos, con montos totales bastante altos. Sin embargo, en relación con estos financiamientos, se han dado varios cuestionamientos entre los que podemos citar:

Varias de estas leyes han sido objeto de múltiples consultas y jurisprudencia, sobre todo, porque no queda clara la condición laboral de las personas educadoras sujetas a esta forma de contratación, en la cual el Estado paga el salario, pero la institución religiosa establece algunos mecanismos de contratación y de permanencia del personal en dichos centros.

Otro elemento que, en diferentes momentos ha estado en cuestionamiento, es que se les ofrece financiamiento porque son organizaciones de bienestar social; sin embargo, el porcentaje de becas que otorgan es muy bajo, ya que solo se les pide becar a $10 \%$ de su población. Además, algunas de estas instituciones educativas cobran, en algunos casos, montos bastante altos por matrículas y colegiaturas, por ende, el carácter de bienestar social no está claro.

De la misma manera la otra base que sustenta el financiamiento que se le brinda a estos centros educativos privados es el supuesto de que tienen un proyecto educativo alternativo. Este aspecto, hasta el momento, no está del 
todo claro, pues no se conocen las particularidades del proceso, ya que lo único que regula el MEP es el cumplimiento de los temarios respectivos.

Según la entrevista realizada al funcionario Mainor Villalobos del MEP, la labor de la Dirección de Educación Privada no tiene potestades de fiscalización, ya que esta no está clara en la legislación. Por ejemplo, el funcionario planteó, en la entrevista, que cuando se hace la solicitud a estas instituciones para que participen en las pruebas PISA (son las pruebas del Programa para la Evaluación Internacional de Alumnos de la OCDE) algunos de estos centros educativos que reciben financiamiento rechazan participar, pues informan que ellos están obligados a ser parte de las pruebas nacionales, pero no de internacionales, y no existe, desde el MEP, ningún mecanismo para obligarlas a participar.

En resumen, es una situación preocupante porque se está girando una cantidad significativa de dinero, pero la posibilidad de fiscalizar y de regular es limitada y en muchos casos nula.

Financiamiento por donaciones de instituciones estatales por la Ley 7266 "Autorización a instituciones descentralizadas y empresas públicas del Estado para hacer donaciones a Fundación para Restauración de Catedral Metropolitana y otros templos y monumentos católicos y empresas privadas a deducir impuesto sobre la renta"

La Ley 7266 titulada "Autorización a instituciones descentralizadas y empresas públicas del Estado para hacer donaciones a Fundación para Restauración de Catedral Metropolitana y otros templos y monumentos católicos y empresas privadas a deducir impuesto sobre la renta" de 1991, consta de tan solo cuatro artículos y plantea lo siguiente:

Artículo 1. Se autoriza a las instituciones descentralizadas y a las empresas públicas del Estado, para que hagan donaciones en favor de la "Fundación para la Restauración de la Catedral Metropolitana y otros Templos y Monumentos Católicos", inscrita en el tomo 105, folio 23, asiento 66, de la Sección de Personas del Registro Público.

De esta forma, las instituciones descentralizadas y empresas públicas del Estado pueden canalizar, de sus presupuestos, partidas concretas para alguna de las temporalidades de la Iglesia católica que, como hemos analizado en otros apartados del trabajo, es la entidad jurídica que administra los bienes materiales de esta institución. 
Para conocer el monto recaudado por este mecanismo, se hizo consulta a la Dirección General de Hacienda. Al solicitarle el monto de fondos públicos que son canalizados a dicha fundación, la directora de este despacho, Priscilla Piedra Campos, mediante oficio DHG-135-2018, responde lo siguiente:

El monto total o desglosado por institución pública o privada debe ser solicitado a la Curia Metropolitana. Si bien la declaración del impuesto sobre la renta tiene una casilla específica para créditos fiscales, esta es general y no permite identificar cuáles instituciones o empresas donaron y por qué monto a la "Fundación para la Restauración de la Catedral Metropolitana y otros Templos y Monumentos Católicos", respecto a créditos por otros conceptos.

En la eventualidad de que se contara con dichos aportes por empresa o institución, estos no se podrían proporcionar, de acuerdo con lo dispuesto en el artículo 117 el Código de Normas y Procedimientos Tributarios, que señala que la información de terceros es confidencial.

Esta respuesta del Ministerio de Hacienda la consideramos insuficiente, ya que estamos haciendo referencia a fondos públicos de instituciones estatales que son canalizadas a una organización religiosa como es dicha fundación, de manera que esta información debería ser catalogada como pública. A pesar de esto, parece que la legalidad permite que tales fondos, al ser girados a una organización de carácter privado como lo es una fundación, esta información quede cubierta dentro de dicho Código de Normas y Procedimientos Tributarios que, en su artículo 117, dicta lo siguiente:

Artículo 117. Carácter confidencial de las informaciones. Las informaciones que la Administración Tributaria obtenga de los contribuyentes, responsables y terceros, por cualquier medio, tienen carácter confidencial; y sus funcionarios y empleados no pueden divulgar en forma alguna la cuantía u origen de las rentas, ni ningún otro dato que figure en las declaraciones, ni deben permitir que estas o sus copias, libros o documentos, que contengan ex- 
tractos o referencia de ellas sean vistos por otras personas que las encargadas en la Administración de velar por el cumplimiento de las disposiciones legales reguladoras de los tributos a su cargo.

No obstante lo dispuesto en el párrafo anterior, el contribuyente, su representante legal o cualquier otra persona debidamente autorizada por aquel, pueden examinar los datos y anexos consignados en sus respectivas declaraciones juradas. Igualmente, cualquier expediente que contemple ajustes o reclamaciones formuladas sobre dichas declaraciones.

A partir de dicha normativa, para esta investigación, nos resulta imposible generar entonces los montos que el Estado deja de percibir por el trato diferencial que se les da a las temporalidades de la Iglesia católica que permiten, con esta ley, que se canalicen fondos públicos para restauración de templos.

En este punto, se destaca que tal ley generó interés de un partido minoritario durante el anterior periodo legislativo, pues sobre este tema el diputado libertario Otto Guevara presentó un proyecto de ley bajo el expediente 19844 con el que pretendía derogarla; lo entregó el 27 de enero del 2016. El diputado centró su atención en la canalización que se hace desde la empresa privada. Al respecto, el diputado argumentó que Hacienda está dejando de recibir ingresos necesarios, ya que muchas empresas están donando a esta fundación y ese dinero no está ingresando al ministerio. En el proyecto de ley se plantea:

La Ley 7266 establece privilegios otorgados desde 1991 a la Fundación para la Restauración de la Catedral Metropolitana y otros Templos Católicos, pero esta ley se dio en un momento histórico específico y de necesidad ante los embates de los enjambres sísmicos que afectaron Costa Rica al principio de la década de los noventa. La Ley 7266 pretendía solucionar un problema que afectó a la edificación de la Catedral Metropolitana, como producto de los terremotos de 1991 y 1992, para mejorar únicamente las condiciones de ese templo y algunos otros también afectados. El propósito por el cual fue creada dicha ley cumplió su objetivo años atrás, ya que la restauración de la Catedral Metropolitana fue culminada en su 
totalidad, y tuvo un costo nominal de unos $\phi 1028$ millones $(2016,2)$.

Como se observa en la cita anterior, este diputado remite al contexto de creación de la ley que se origina en el marco de los daños ocasionados por terremotos en 1991 y 1992 y, por tanto plantea el interés de derogar esta normativa al haber cambiado el contexto. Sin embargo, el proyecto de ley vencía el 13 de marzo del 2018 y no se realizó mayor debate sobre este, de manera que posiblemente sea archivado, aunque por lo reciente del vencimiento, no se ha dado trámite.

\section{Exoneraciones de impuestos territoriales}

Finalmente, al hacer referencia a las exoneraciones de impuestos de los cuales la Iglesia católica es objeto, debemos citar la Ley 7509 Ley Impuesto sobre Bienes Inmuebles y su reforma Ley 7729 , la cual, en su artículo 4, define cuáles son los inmuebles no afectados por el impuesto, y en el inciso g) define lo siguiente:

g) Los inmuebles pertenecientes a iglesias y organizaciones religiosas pero solo los que se dediquen al culto; además, los bienes correspondientes a las temporalidades de la Iglesia católica: la Conferencia Episcopal de Costa Rica, la Arquidiócesis y las diócesis del país.

En relación con esta exoneración y según consulta realizada a la Dirección General de Hacienda del Ministerio de Hacienda (oficio DGH-135-2018), esta entidad no tiene ningún consolidado de este monto en sus registros, ya que como lo establece la Ley 7729 , en su artículo 3, el control de estos corresponde a las municipalidades.

De esta manera, se les tendría que hacer la consulta a las 82 municipalidades existentes en el país para dimensionar el monto de esta exoneración. Tal consulta no es posible concretar, ya que, al ser bienes inmuebles en muchos casos muy antiguos e, históricamente, desde su creación, exonerados de este impuesto (como lo vimos en el primer apartado de este artículo) no existe una valoración económica del precio de la propiedad actualizada con un perito.

A partir de esto, se intenta hacer la consulta a la Municipalidad de San José sobre la posibilidad de hacer una estimación de los montos de pago de impuestos de las edificaciones de la Iglesia católica dentro de su rango de ac- 
ción, solo para conocer si existe algún dato general al respecto. Para esto la consulta fue realizada al ingeniero Edwin Hernández Valerio del Departamento de Proceso de Valoraciones de Bienes Inmuebles de esa municipalidad. Al respecto, el funcionario nos contesta vía correo electrónico lo siguiente:

En respuesta a su consulta le indico que, en este municipio, hay 64 propiedades a nombre de las Temporalidades de la Arquidiócesis de San José. En cuanto al valor de las propiedades y el impuesto de bienes inmuebles que podrían generar, no se cuenta con información, debido a que la gran mayoría de ellas no están declaradas ni han sido valoradas por esta municipalidad por razones obvias.

En conclusión, no existen peritajes para ver los valores estimados de estas propiedades. Parece que la naturalización de la no recaudación de edificaciones de las temporalidades de la Iglesia católica hace que la institucionalidad ni siquiera se cuestione el posible conocimiento del valor de dichas estructuras.

\section{Reflexiones finales}

A partir de los planteamientos expuestos para tratar de hacer visibles los mecanismos de financiamiento y los montos que se asignan por parte del Estado a la Iglesia católica, quisiéramos hacer algunas reflexiones de cierre, aunque sabemos que es un tema cuya discusión apenas inicia en el país.

Se evidencia cómo una decisión que se toma en un contexto de un Estado costarricense incipiente, en el cual las élites cafetaleras no quieren pagar diezmo y el gobernante Mora Porras asume financiar los pocos clérigos de la época, ha generado hasta la actualidad un entramado de legislaciones y de acciones que cuestan un alto monto a las arcas del Estado.

Con el pasar del tiempo, los mecanismos de financiamiento se han ido ampliando y no se han cuestionado estos montos que, como vemos, son en algunos casos, como en el del MEP, bastante altos. Así en términos de política pública, la declaración de confesionalidad del Estado genera una canalización significativa de fondos anuales de presupuestos públicos.

Conociendo estos montos de cuánto cuesta un Estado confesional en la Costa Rica contemporánea y en un contexto de crisis fiscal, en el cual se plantea una serie de recortes de fondos públicos para sanear las finanzas estatales, es fundamental evidenciar cómo no se cuestiona la posibilidad de hacer al- 
gún recorte a estas asignaciones presupuestarias. Evidentemente, surge en este punto la pregunta: ¿por qué el Estado costarricense direcciona tantos fondos a la Iglesia católica?, ¿en qué se basa esta relación?

En la historia de Costa Rica, la Iglesia ha tenido un papel relevante en la legitimación del poder político y, en diferentes momentos de la vida nacional, ha tenido diversos papeles de santificadora del poder por medio de una serie de mecanismos simbólicos; de legitimadora de acciones gubernamentales; y de mediadora entre sectores en momentos de conflicto. Siempre ha llamado a la calma, al mandato del orden y al respeto a la autoridad.

De manera que lo que se ha gestado entre ambos actores es una relación de intercambio de favores, en la cual el Estado recibe legitimación de un actor religioso que, hasta hace algunos años, tenía un fuerte poder en un país con población mayoritariamente católica. A cambio, la Iglesia recibe, como vemos, no poco dinero para gestionar sus proyectos en el territorio nacional.

Es necesario recordar que esta aprobación de legislación se da por acuerdos en Asamblea Legislativa y por los años de aprobación de las leyes citadas en este trabajo. Así se está hablando de acuerdos entre las fracciones entre PUSC-PLN y la Conferencia Episcopal para financiar a la Iglesia en el territorio.

Ahora bien, estos pactos realizados para la canalización de fondos estatales no se han dado sin reacción de sectores, fundamentalmente en los últimos diez años; por ejemplo, quienes se aglutinan alrededor del llamado el Movimiento por un Estado laico, en el que participan: sectores de feministas, ecologistas, estudiantes, académicos, etc., y conforman un actor colectivo diverso que ha logrado una relativa visibilidad social.

Además de esto, se han presentado, en los últimos años, tres proyectos de ley para la declaratoria de Costa Rica como Estado Laico, a partir de la modificación de varios artículos constitucionales, los cuales citamos brevemente a continuación:

- El proyecto de ley 15452 del año 2003 planteaba la reforma al artículo 75 de la Constitución Política, pero en revisión del expediente en el Archivo de la Asamblea Legislativa, se constató que este proyecto no tuvo ningún proceso de debate y ni siquiera fue enviado a ninguna comisión para dictaminarse. Lo único que se encuentra en el respectivo expediente es un comunicado del 16 de octubre del 2007 en el que señala que, por haber trascurrido 4 años calendario, se vence el plazo del proyecto y pasa al archivo.

- El proyecto 17511 plantea la reforma a los artículos 75 y 194 de la Constitución Política. En este caso, el proceso es bastante interesante pues, en principio, varios diputados firman esta iniciativa; sin embargo, ante el peso del debate en la opinión pública por la presentación del proyecto, en los días siguientes, cuatro diputados presentan cartas pidiendo que se retire su firma. Con el retiro de estas firmas y 
al carecer de la cantidad de firmas de diputados necesarias, el proyecto es retirado en setiembre de ese mismo año y no se discute.

- El proyecto de ley 18496 presentado en el 2012 pretende, también, modificar los artículos 75 y 194 de la Constitución, cuyo plazo vencía en junio 2016, pero en marzo del 2016 mediante decreto ejecutivo, el presidente de la república convoca a ser votado en periodo de sesiones extraordinarias. En cuanto a revisar el expediente legislativo de ese proyecto de ley es importante señalar que en ese periodo, no se da mayor discusión del mismo.

En este contexto donde el tema se está empezando a discutir desde diferentes sectores, es necesario plantear que el debate por la laicidad del Estado no es solo filosófico y político de total relevancia, sino que tiene un correlato práctico. Esto debido a que estamos hablando de la posibilidad real de recortar presupuesto estatal que se le ha asignado por acuerdos políticos a este actor. Para ello, uno de los primeros pasos era conocer el costo presupuestario de un Estado confesional en la actualidad, aspecto al que pretende aportar este texto.

Además, es relevante tener claro que al día de hoy hablar de la posibilidad de que un Estado laico trasciende la modificación de dos artículos constitucionales, pues implica revisar leyes, decretos, jurisprudencia, pero fundamentalmente, prácticas políticas y burocráticas anquilosadas en las lógicas institucionales. Como vemos en las cinco vías en estudio, no existe en la legislación (salvo el caso de una de las leyes del MEP) un monto específico escrito de lo que se debe asignar a las temporalidades de la Iglesia, sino que, desde la institucionalidad, se ha ido construyendo. Esto hace que el cambio nece sario, para un estado laico, pase por la revisión de dichas prácticas de legitimidad social del financiamiento.

Finalmente, para dimensionar su accionar y vencer la opacidad de estos temas en la discusión, se debe evidenciar a la Iglesia como un actor económico. El interés de este artículo es empezar a generar información de direccionamientos de fondos que se hacen desde el Estado; y como mencionamos anteriormente en un contexto de crisis fiscal, es necesario mirar estas cifras, tanto las que se pudieron generar en este proceso como las que no se pudieron conocer. Así, se amplía la discusión de si en la Costa Rica actual es necesario y prioritario dar estos financiamientos, o bien en nuevos contextos sociales, ya podemos prescindir de ellos.

\section{Bibliografía}

García, Rolando. 2012. «La iglesia católica como sujeto de derecho internacional: implicaciones jurídicas del establecimiento de un estado Laico; y el concordato como mecanismo de protección para la iglesia». 
Tesis para optar por el grado de licenciatura en Derecho. Universidad de Costa Rica.

Sandí, José. 2012. Estado e Iglesia Católica en Costa Rica 1850-1920: en los procesos de control del espacio geográfico y la creación de un modelo costarricense. Heredia: Universidad Nacional, 2012. 